\title{
Use of oral pathology services by general histopathologists and their attitudes to training of oral pathologists
}

\author{
A W Barrett, P M Speight
}

\section{Abstract}

Aims-(1) To determine whether general histopathologists are aware of oral pathology as a specialist discipline and whether they use oral pathologists to identify lesions of the dental and orofacial tissues which pose diagnostic difficulties to general histopathologists. (2) To establish whether consultant histopathologists would consider dentally qualified applicants for salaried training posts within their department so that they may fulfil College accreditation requirements.

Methods-A questionnaire was sent to a consultant histopathologist in each of 226 general histopathology departments in England and Wales.

Results-In total, 167 (74\%) consultant histopathologists completed the questionnaire, of whom $98 \%(163 / 167)$ were aware of the specialty and $92 \%(153 / 167)$ perceived a need for it. Oral biopsy specimens formed less than $5 \%$ of the workload in $76 \%(126 / 167)$ of departments, but $80 \%$ (134/167) of the consultants had referred at least one case to an oral pathologist during 1993. The most common sources of diagnostic difficulty were identified as salivary gland pathology, odontogenic tumours and lesions of oral mucosa. Only $22 \%(36 / 167)$ of consultants were aware that trainees in oral pathology are obliged to spend a year in accredited general histopathology training, but $40 \%(67 / 167)$ said they would consider a dentally qualified applicant for a training post in their department.

Conclusions-General histopathologists are aware that oral pathologists exist and most will at some time call on their services; thus there is a need for specialists in oral pathology. Consultant histopathologists have a supportive attitude to the problem of providing the necessary general experience for oral pathology trainees, which will continue to be obtained through secondment to a histopathology department outside the trainee's main institution in most cases. Central funding would help the problem of providing cover for trainees spending a year out to complete general pathology training. (F Clin Pathol 1996;49:565-569)

Keywords: oral pathology, general histopathology, training, accreditation.
Departments of Oral Pathology in the 14 dental schools in the UK provide a routine diagnostic pathology service for their associated dental hospitals and a specialist referral service for general histopathologists who may be confronted with an unfamiliar lesion of the teeth, jaws, oral mucosa, or salivary glands. There are less than 30 oral histopathologists currently practising in the UK who have passed the MRCPath diploma by examination. The regulations governing the $M R C P a t h$ require trainees in oral pathology to undergo one year's training in general histopathology before they are allowed to sit the Part I- examination. At present, most trainees hold academic appointments within dental schools; research and teaching are thus major components of their duties, as well as participation in the diagnostic service. As a result, acquiring the necessary general pathology experience poses a considerable problem, both for dentists intending to sit the MRCPath examination and the academic department employing them. There is no formalised method of funding or organising this training and most trainees are attached to a general pathology department on an ad hoc arrangement which relies heavily on personal contacts and the goodwill of the host department.

Despite papers that have stressed the value of oral pathology services, ${ }^{1}$ there are currently no published data on the use of such services by general histopathologists, either in the UK or abroad. The purpose of this study was to determine the extent to which individual general histopathologists are aware of oral pathology as a specialist discipline, whether general histopathologists perceive a need for, and use, oral pathologists, to identify lesions of the dental and orofacial tissues which pose diagnostic difficulties. In view of the training requirements, we also wished to establish whether consultant histopathologists would consider dentally qualified applicants for salaried training posts within their department.

\section{Methods}

From lists in the Medical Directory 1994 and Royal College of Pathologists Directory 1993, one consultant from each of 226 general histopathology departments in medical schools, and general and specialist hospitals in England and Wales was randomly selected for the survey, which took the form of a "tick box" questionnaire. Each consultant was initially asked about oral pathologists and oral pathol- 
Table 1 Questions asked regarding use of oral histopathologists and oral pathology workload

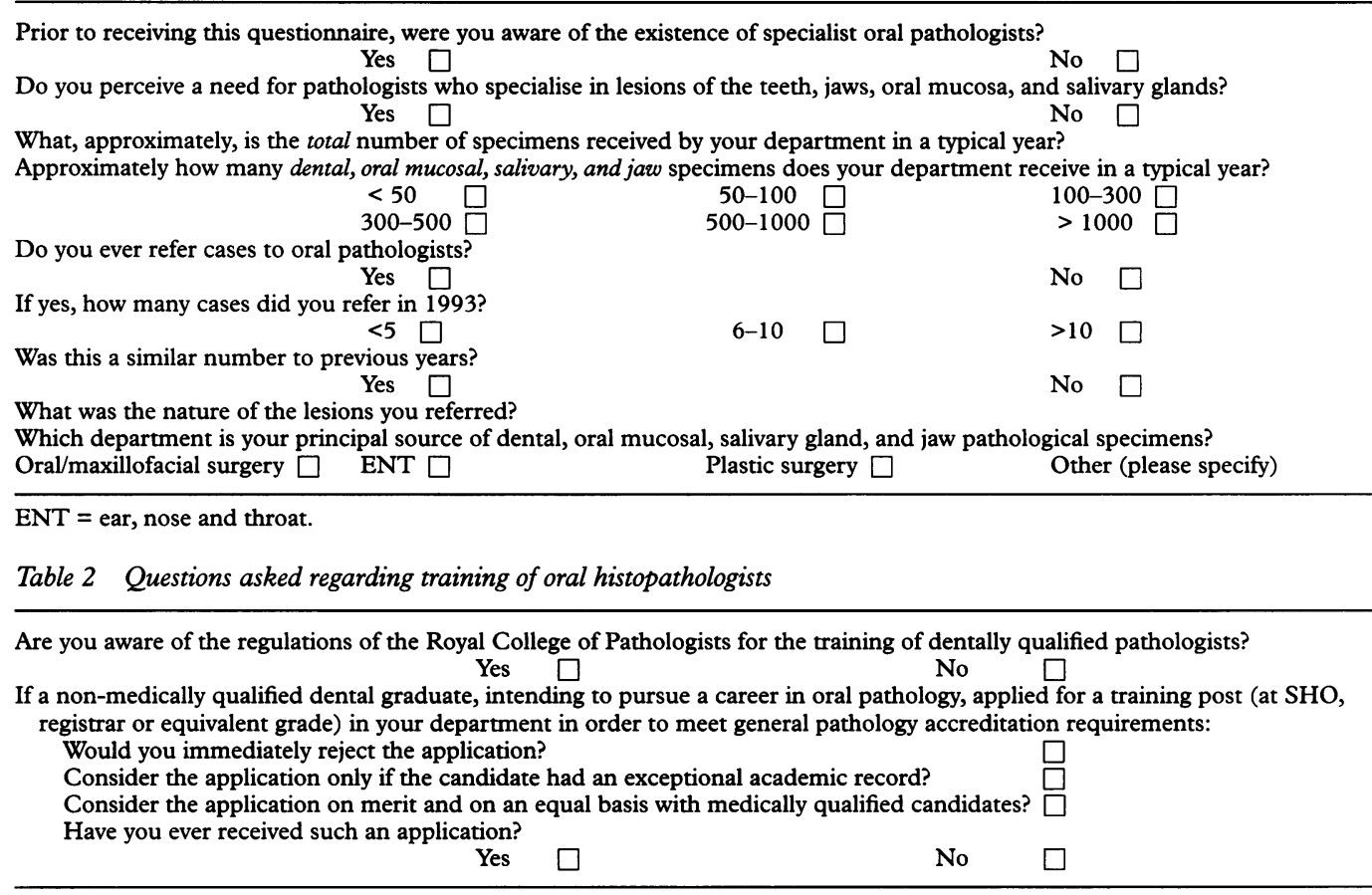

ogy workload (table 1). The upper limit of each numerical category of oral pathology workload was used to estimate it as a proportion of the total annual workload of the department. To determine the nature of the lesions referred to oral pathologists, the consultant was given the choice of odontogenic (cysts and tumours), bony, antral, salivary, mucosal (inflammatory, dysplastic or neoplastic) or "other". The final questions pertained to the training of oral pathologists (table 2). Additional comments on this or any other topic raised were then invited. Each questionnaire was accompanied by a covering letter and a stamped addressed reply envelope. A single reminder letter and further questionnaire were sent to non-respondents after eight weeks.

\section{Results}

Completed questionnaires were received from $167(73.9 \%)$ consultants. Of these, 163 $(97.6 \%)$ were aware of specialist oral pathologists prior to receiving the questionnaire, and $153(91.6 \%)$ perceived a need for them. Specific comments to the effect that specialists were needed in this branch of pathology, as they were for other sites and systems, were made on $35(21.1 \%)$ occasions. In contrast, seven $(4.2 \%)$ consultants felt that oral pathology was better served as an interest of general histopathologists, rather than as a full-time specialty. Two consultants commented that they had an interest in head and neck pathology, and one had spent time as a lecturer in an oral pathology department. One consultant found clinicopathological conferences attended by an oral pathologist "very educational" and two others thought there should be greater interaction between general and oral pathologists.

The number of surgical requests received by each department ranged from 3000 to 36000 . The numbers of dental, oral mucosal, salivary,
Table 3 Number of dental, oral mucosal, salivary, and jaw specimens received by 167 general histopathology departments in a typical year

\begin{tabular}{lc}
\hline Requests received & Number of departments (\%) \\
\hline$<50$ & $42(25.1)$ \\
$50-100$ & $36(21.6)$ \\
$100-300$ & $46(27.5)$ \\
$300-50$ & $26(15.6)$ \\
$500-1000$ & $14(8.4)$ \\
$>1000$ & $3(1.8)$ \\
Total & $167(100.0)$ \\
\hline
\end{tabular}

Table 4 Upper limit (as in column 1, table 3) of number of dental, oral mucosal, salivary, and jaw specimens received by 167 general histopathology departments expressed as a percentage of the total departmental workload

\begin{tabular}{lc}
\hline Proportion of departmental workload (\%) & $\begin{array}{l}\text { Number of } \\
\text { departments (\%) }\end{array}$ \\
\hline$<1.0$ & $45(26.9)$ \\
$1.1-5.0$ & $81(48.5)$ \\
$5.1-10.0$ & $26(15.6)$ \\
$>10.1 \%$ & $1(0.6)$ \\
Total number of requests received not & $14(8.4)$ \\
$\quad$ specified on completed questionnaire & $167(100.0)$ \\
Total &
\end{tabular}

and jaw specimens received by each department are shown in table 3 , with the estimated percentages of respondents in each category of workload detailed in table 4. In $126(75.5 \%)$ departments material from these sites constituted $5 \%$ or less of the workload and in 45 $(26.9 \%)$, less than $1 \%$. Ten $(6.0 \%)$ consultants, eight of whom received less than 50 oral specimens annually, said that most material went directly to the oral pathology department in the local dental hospital. Principal sources of biopsy specimens from the sites in question are shown in table 5. One consultant observed that his workload from the head and neck had increased substantially in recent years.

In $1993,134(80.2 \%)$ consultant histopathologists had referred cases to oral pathologists. Of these $118(88.1 \%)$ did so on 
Table 5 Principal sources of pathological material from oral and perioral structures (includes instances where more than one department was nominated)

\begin{tabular}{|c|c|c|}
\hline Surgical source & \multicolumn{2}{|c|}{$\begin{array}{l}\text { Instances (1167) as } \\
\text { principal source (\%) }\end{array}$} \\
\hline $\begin{array}{l}\text { Oral and maxillofacial surgery } \\
\text { Ear, nose and throat } \\
\text { Plastic surgery } \\
\text { General surgery } \\
\text { General dental practitioners }\end{array}$ & \multicolumn{2}{|c|}{$\begin{aligned} & 123(73.7) \\
& 55(32.9) \\
& 8(4.8) \\
& 8(4.8) \\
& 7(4.2)\end{aligned}$} \\
\hline \multirow{2}{*}{\multicolumn{3}{|c|}{$\begin{array}{l}\text { "Other" principal sources nominated on one occasion each } \\
\text { were: general medical practitioners, "referrals", oral medicine, } \\
\text { and "general practice". } \\
\text { Table } 6 \text { Pathological nature of lesions referred by } 134 \\
\text { general histopathologists }\end{array}$}} \\
\hline & & \\
\hline Type of lesion & Instances & $\begin{array}{l}\text { Per cent of } \\
134 \text { who } \\
\text { referred }\end{array}$ \\
\hline Salivary gland lesions & 81 & 60.5 \\
\hline Odontogenic tumours & 59 & 44.0 \\
\hline Neoplastic mucosal lesions & 31 & 23.9 \\
\hline Inflammatory mucosal lesions & 29 & 22.4 \\
\hline Other maxillary bony lesions & 26 & 19.4 \\
\hline Dysplastic oral mucosal lesions & 25 & 18.7 \\
\hline Other mandibular bony lesions & 20 & 14.9 \\
\hline Odontogenic cysts & 17 & 12.6 \\
\hline Lesions from the maxillary antrum & 11 & 8.2 \\
\hline
\end{tabular}

Other causes of referral specified were metastatic carcinoma in neck, "soft tissue entities and oral lymphomas", "an unerupted tooth", "tooth", and "postmortem dental identification" on

one occasion each.

fewer than five occasions, but $17(10.2 \%)$ had referred more than five cases in 1993 and two had referred more than 10. Salivary gland lesions and odontogenic tumours were the main sources of difficulty (table 6), but $18-24 \%$ sought second opinions on conditions of the oral mucosa. One consultant commented that "salivary gland tumours need sorting out again" and one routinely sent all his to the Salivary Gland Tumour Panel, at the latter's request. Only two consultants mentioned that they had received specialist training in oral pathology as juniors, and four thought that general histopathologists did not see enough oral pathology to diagnose difficult cases with confidence. Two suggested there was a need for more short courses on which oral pathology was taught. In contrast, six respondents regarded salivary gland pathology as well within the remit of a general histopathologist, and two said they did refer salivary cases, but not to oral pathologists. Another referred oral "soft tissue entities and lymphomas", but again not to an oral pathologist. Two others felt that oral pathologists were needed for "teeth only".

Only $36(21.6 \%)$ consultants who replied were aware of the regulations of the Royal College of Pathologists for the training of dentally qualified histopathologists, but $67(40.1 \%)$ said they would consider a non-medically qualified dental graduate who applied for a training post on merit and on an equal basis with medically qualified candidates. Two specified that they would need evidence that the candidate already had some experience of general pathology. However, it was clear from six of the comments appended that this question had been misinterpreted to mean that the applicant would only be expected to handle oral and perioral material, rather than participate fully in all aspects of the department including preparation of large, non-oral resections and postmortems. Fifty (29.2\%) consultants stated that they would reject a dental applicant outright, and $12(7.2 \%)$ that they would only consider a dental applicant with an exceptional academic record. The remainder either did not express an opinion, or concluded the question was hypothetical as there were no training posts in their department. Indeed, 53 $(31.7 \%)$ did not have training posts.

Of those who would reject a dental graduate outright, nine expressed reservations about their ability to perform the tasks required, especially in a district general hospital department. In particular, it was felt a dentist would struggle with cytopathology, necropsies and trimming of large resections. Another raised the fact that the trainee would be expected to teach medical students. Two respondents said that in view of the fact that any pathological entity may affect the head and neck, all pathologists should have a full medical training. Eight consultants pointed out that junior appointments are often made at a regional level, and that some appointments would require the appointee to rotate around other medical specialties. One respondent commented that, whilst he would have been happy to consider a dental applicant, he doubted "the management" would allow such an appointment. Nevertheless, three consultants said they fully appreciated the need to train a potential oral pathologist in general matters and four said they would welcome a dental trainee on a part-time or secondment basis. Only one consultant had ever received an application from a dentist.

\section{Discussion}

There is concern in some quarters that a career in oral pathology is an unattractive option ${ }^{2}$ and, in the UK, oral pathology certainly attracts few dental graduates compared with other dental specialties. However, this may be just as well, as, with only 14 centres, training opportunities and senior posts present themselves infrequently. The training pathway for oral pathologists has recently been restructured to conform to the five year pathway followed by general histopathologists. ${ }^{3}$ One important difference is the obligatory year of full time general pathology in a recognised department in the three year period prior to sitting the MRCPath Part I examination. As all oral pathology trainees in the UK are employed in dental schools, general experience must be acquired outside their parent department or institution. A further two years higher specialist training in oral pathology is required, at which point the trainee sits the MRCPath Part II examination to become accredited.

As an academic based specialty, it is uncertain how the implementation of the Chief Medical Officer's proposals for Specialist Registrar training ${ }^{4}$ will affect trainees in oral pathology, or whether oral pathology will keep step with histopathology when transitional arrangements begin in 1996. In the report from the Chief Dental Officer, which considered future development of dental specialties, ${ }^{5}$ 
oral pathology was included as an "additional dental specialty" for which it was recommended the General Dental Council establish a specialist list and curriculum.

The training of oral pathologists has always been the remit of the Royal College of Pathologists, however, and the requirement for general training suggests that the Calman proposals will affect oral pathologists. Although only $22 \%$ of respondents were aware of College regulations regarding oral pathology, we were surprised that so many consultant histopathologists (over 40\%) were prepared to consider a dental graduate without a medical qualification for training posts in their department. Reductions in junior histopathology training posts nationwide and the appointment of Specialist Registrars for the term required to complete accreditation means it is unlikely that a consultant histopathologist would select a dentist over a medically qualified applicant and, as several pointed out, appointing a dentist may be impractical on a regional rotation or if duties are allocated in other branches of medicine. Nevertheless, one consultant commented that each application should be considered on merit "especially in the current climate of decreasing junior staff availability".

Hitherto, the alternatives to accredited training posts have been "visitor" appointments, usually awarded to overseas trainees not holding right of permanent UK residence, and secondment to a histopathology department on an ad hoc basis. It has been our own experience that general histopathology departments will consider British oral pathology trainees for "visitor" appointments if overseas candidates are unavailable. In such a position, the oral pathologist will not occupy an accredited general histopathology training post and is not, in any case, eligible for a general histopathology consultant appointment. Many departments are also happy to have oral pathology trainees on secondment to their department carrying out a wide range of duties under supervision. Although secondment is likely to remain the commonest means of obtaining the necessary general pathology accreditation, once the Chief Medical Officer's proposals are in operation it may be possible for oral pathology trainees to apply for a fixedterm training appointment (FTTA). ${ }^{4}$ This will not attract a histopathology national training number, but will be recognised towards the individual's oral pathology CCST (Certificate of Completion of Specialist Training).

Appointment to a full-time training post would enable the oral pathology trainee to complete the most problematical stage of his training unencumbered by the teaching and research responsibilities which inevitably accompany academic posts. There are, however, inevitable manpower strains in the parent department while the trainee is away, a problem to which there is no straightforward solution. In the current financial climate, it is unlikely that funding would be made available to pay for cover (either in the form of a FTTA or short term locum appointment ${ }^{4}$ ) during this period, though it might be pointed out that, given the small number of oral pathology trainees, the need for this cover is neither regular nor frequent.

With mounting pressure on academics to "perform" in terms of publications and grant $\bar{C}$ awards, it may also be that universities will $\overline{\bar{J}}$ become less disposed to permit their employ- 7 ees (as oral pathology trainees invariably are) $\overrightarrow{\vec{\sigma}}$ to spend a year on pursuits of no immediate. benefit to the academic environment, and even $\overrightarrow{\vec{F}}$ less to support the expense of a temporary $\frac{\vec{P}}{0}$ replacement. Funding for the routine histopa- $\frac{\bar{O}}{0}$ thology service provided by university dental $\overline{\bar{c}}$ schools comes from a variety of sources, $\mathbb{\otimes}$ including the Higher Education Funding Council, the Department of Health via SIFT, or from within the NHS. However, this survey? shows that many general histopathologists seek $\vec{\overrightarrow{ }}$ the opinion of an oral pathologist at some time, $\stackrel{\omega}{\circ}$ a process that in the future may be governed by용 the arrangements for tertiary extra-contractual i referrals. ${ }^{6}$ This, and the introduction of Trust $-v$ status, may necessitate oral pathologists charg- ir ing for their services. Whilst most might be expected to gradually accept this philosophy for routine cases, the possibility of financial $\vec{c}$ considerations interfering with the free transfer of knowledge will concern all referring and specialist histopathologists not accustomed to $\mathscr{\oslash}$ such constraints. It has been the view of the Royal College of Pathologists that consultants should not charge each other for second opinions where these are not a substantial part of the department's workload (Lachmann PJ, $\frac{\mathscr{Q}}{\mathbb{D}}$

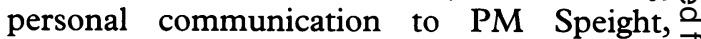
1993). For example, if referrals constitute less than $10 \%$ of the total number of requests, the extra costs may be insignificant enough to be absorbed within the departmental budget. If this proves to be the case most, if not all, oral용 pathology departments in the UK could allow current arrangements to continue, with few likely to run into the problems faced by a unit $\frac{\delta}{\gamma}$ functioning primarily as a referral service.

The emphasis placed on the embryology, 음 anatomy and pathology of the head and neck in $\frac{D}{0}$ dental undergraduate and postgraduate teaching means oral pathologists are ideally suited to $\widetilde{\sim}$ the histological interpretation of lesions affect- $N$ ing this region and it is perhaps not surprising $N$ that salivary gland and odontogenic lesions are $\omega$ the commonest cause of referral (table 6). Similarly, the fact that approximately one fifth to one quarter of general histopathologists $\stackrel{\oplus}{?}$ referred cases of oral mucosal disease reflects $T$ the limited exposure to oral and perioral lesions they received as students, junior clinicians and, it seems, as histopathology trainees. $\stackrel{\mathbb{Q}}{\square}$

We conclude that almost all general histopathologists are aware of oral pathologists and, though capable of dealing with most of the small workload posed by oral lesions, refer cases where necessary. This study therefore confirms that there is a continuing demand for expertise in oral pathology, which should be maintained as a specialist branch of histopathology. Whilst $80 \%$ of the training can be carried out within the trainee's base department, the remainder must be acquired externally in a 
general histopathology department. Unless the trainee is able to secure a training post in such a department independently, other responsibilities in teaching and research will render it difficult for mandatory general pathology training requirements to be fulfilled. Central funding to provide cover for the trainee in this predicament may alleviate the problem.

The authors thank all the consultant histopathologists who took the trouble to complete and return our questionnaire.

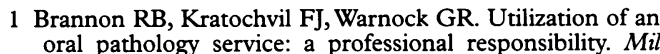
Med 1992;157:31-2.
2 Allen CM "I'd really like to be an oral pathologist, but. ". Oral Surg Oral Med Oral Pathol 1995;80:251.

3 Royal College of Pathologists. Regulations and Guidelines for College Examinations. London: Royal College of Pathologists, 1993.

4 Department of Health. A guide to Specialist Registrar training. London: Department of Health, 1995:51-3.

5 Department of Health. UK Specialist Dental Training. Report from the Chief Dental Officer. London: Department of Health, 1995:47.

6 Department of Health. Guidance on the revised operation of notification arrangements for tertiary extra contractual referrals. [HSG(95)20]. London: Department of Health, referrals.

7 Fletcher CDM. The deleterious effect of the NHS reforms on specialist referral services in histopathology: a personal view. ACP News 1995;Autumn:4-5. 